\title{
Assessment of Accountability Practices in the Public Sector of Malaysia
}

\author{
Jamaliah Said \\ Accounting Research Institute \\ Universiti Teknologi MARA \\ Shah Alam, Malaysia \\ Email: jamaliah533@salam.uitm.edu.my
}

Md. Mahmudul Alam*

School of Economics, Finance and Banking

Universiti Utara Malaysia

E-mail: rony000@gmail.com

\author{
Razana Juhaida Johari \\ Faculty of Accountancy \\ Universiti Teknologi MARA \\ Shah Alam, Malaysia \\ Email: razana@salam.uitm.edu.my
}

*correspondent author

\section{Citation Reference:}

Said, J., Alam, M.M., \& Johari, R.J. (2018). Assessment of Accountability Practices in the Public Sector of Malaysia. Asia-Pacific Management Accounting Journal. 13(1), 167-184.

http://arionline.uitm.edu.my/ojs/index.php/APMAJ/article/view/726 (online)

This is a pre-publication copy.

The published article is copyrighted by the publisher of the journal. 


\title{
Assessment of Accountability Practices in the Public Sector of Malaysia
}

\begin{abstract}
Ensuring accountability in the public sector is a very crucial issue as it could lead to failures in governance, fraud, inefficacy, corruption as well as weak financial management. This study evaluated the state of present accountability practices among public sector employees from various Malaysian service schemes. Primary data were collected, using a questionnaire survey approach with 194 heads of departments in the Malaysian federal ministries. Data was collected in accordance with the perspective of 12 factors in accountability practices, using a five-point Likert scale. Factor analysis and descriptive statistics were utilized for data analysis. In addition, data reliability was checked by Cronbach's alpha test; data normality was examined by Skewness and Kurtosis tests, and data validity was tested by using KaiserMeyer Olkin test and Barlett's test. The findings show that $94.9 \%$ of the participants reported that they practised accountability within their departments. Nevertheless, the priority for these accountability factors varied according to the service schemes. In general, the perceived accountability practice was the highest within the group of the administrative scheme and the lowest among the employees under the accounting scheme. Moreover, the perceived accountability practice of the audit scheme was below the general average level. This findings of the study would help policy makers to take necessary steps to improve the practices of accountability in the public sector for creating a more dependable and efficient public sector in Malaysia.
\end{abstract}

Keywords: Public Sector, Accountability, Factor Analysis, Malaysia

\section{Introduction}

Over the past decades, the concept of accountability has become increasingly important in organizational practices since it plays greater role, particularly in public administration (Nyamori, Abdul-Rahaman \& Samkin, 2017; Weistein, 2017; Aziz et al., 2015; Green, Vandekerckhove \& Bessire, 2008). Many authors have defined accountability differently. This is because there are different shades of meanings or interpretations and practices of accountability are found among researchers. The differences in the meaning and practices of accountability are seen vividly through new organization structures that have been introduced in recent decades (Green et al., 2008).

The term accountability cannot be determined accurately since many researchers have extensively debated on its definition. In general, accountability is known as the internal and external duty from an individual or organization to be accountable for their activities, accept responsibility for them and disclose the result in a transparent way, which includes the responsibility for money or other entrusted property (Huse, 2005; Iyoha \& Oyerinde, 2010; Almquist etal., 2013; Aziz et al., 2015). According to Roberts and Scapens (1985), accountability refers to the relationship between the giving and demanding of reasons for any conduct in any organization.

However, the concept of accountability is broad, and every researcher has his or her own opinion and definition in terms of accountability. Differences in defining accountability and broader aspect of the concept of accountability are supported by Nyland and Pettersen (2015), and they have defined accountability, which is related to the nature of the relationship, which generates a diversity of definitions. 
Since accountability is one of the criteria for good governance, the term accountability is conveyed as an image of trustworthiness and transparency of the organization to the public (Said \& Jaafar, 2014). Accountability is always related and has become one of the criteria to good governance because it implies public organizations that conduct the public matters and manage public funds in a way fundamentally free from abuse and corruption as well as obey the rule of law (Morrell, 2009; Bhuiyan \& Amagoh, 2011).

Jayasinghe and Soobaroyen (2009) stated that the role of "trust" was really important to be acknowledged since it was highlighted as a critical factor, underpinning the informal and socializing accountability relationships. Yaakob et al. (2009) added that accountability was often associated with such concepts, such as answerability, blameworthiness, responsibility, liability, and other terms associated with the expectation of accounting. According to Gray et al. (2006), and Nyland and Pettersen (2015), the definition of accountability is related to the rights of society which are stakeholders within society and also the rights that emerge from the relationship between the accountor and the accountee or between the principals and agents. In addition to that, King (1992) defined accountability as a management philosophy by which individuals are held liable or accountable for how well they use their authority and live up to their responsibility of performing the predetermined activities.

Accountability is always related to good governance, and it implies public organizations that conduct public matters, manage public funds and guarantee the realization of human rights in a way fundamentally free from abuse and corruption as well as obey the rule of law (Aziz et al., 2015; Isandla Institute, 2017). That is why, it is important for the organization like public sector to have good governance in order to improve the public trust towards government. In order to ensure the existence of good governance, the factor of accountability is very crucial. Even in politics, accountability is a crucial factor in determining good governance, especially in the representative democratic system (Yaakob et al., 2009).

Therefore, to obtain public trust, a government needs to improve its effectiveness and quality because every citizen or public all over the world has been claiming for better accountability from the government. Accountability in the public sector requires the government to be answerable to the public and be justified about the source and utilization of public resources since the public have the right to know and receive the facts and figures which would assist them to decide the destiny of their elected representatives (Christensen \& Skærbæk, 2007; Lægreid, Verhoest \& Jann, 2008; Jorge de Jesus \& Eirado, 2012; Almquist et al., 2013; Subramaniam, Stewart, Ng \& Shulman, 2013; Gabriel, 2017).

Moreover, Green et al. (2008) added that there were several steps to increase accountability as suggested by Prosen (2006), and the increase of accountability can happen by establishing the organization's top three objectives. The objectives relate assigning each team member his or her objectives, asking each of team member what he or she needs to win, agreeing on what the leader will do to help, doing the follow up, sharing lesson learned, and lastly getting the reward result.

The government of Malaysia recently has realized that in order to achieve the vision of 2020 and the goal to become a high income nation by 2020, the government itself needs to equip the nation with high class mentality citizens with the attitude of upholding high ethical 
value (Iyer, 2011). Therefore, it is affirmed that accountability plays a major role in ensuring the good governance within the organization, especially in the public sector.

This study examines the accountability practices in the public sector of Malaysia. This study has selected Malaysia since quite a number of grave issues are found in the public sector, and they are related to corruption, fraud, governance failures, poor financial management, etc. These occurrences have raised numerous questions or eyebrows about the accountability of the public sector in its obligation to uphold the public's trust. This study hopes to help the government to discover the key factors that would be able to nurture and promote the accountability value in the government sector.

\section{Research Methodology}

\section{Data Collection and Sampling}

This study collected data using a questionnaire survey of the heads of departments of six Malaysian federal ministries from January to June 2016. The six selected ministries included (i) the Ministry of Education, (ii) the Ministry of Communication and Multimedia, (iii) the Ministry of Defence, (iv) the Ministry of Health, (v) the Ministry of Rural and Regional Development, and (vi) the Ministry of Agriculture and Agro-Based Industry. These ministries were chosen as they were the frequently reprimanded ministries in relation to issues, such as integrity, accountability, mismanagement, and ethics in accordance with the Auditor General Report for three consecutive years, i.e. from 2012 to 2014

In total, there are 402 sub-departments under these six ministries. The target sample of the study was 210, and the sample was chosen, using the systematic random sampling method and using every two listed departments under each ministry. The selection process began with a department's second list followed by the fourth list, the sixth list, etc. until it reached 402 and ended up with 210 items in the sample. Lastly, 194 questionnaires from 210 target samples were utilized in analysing data.

\section{Measurements of Variables}

The participants were required to offer their perspective on the practices that promote accountability in their department by utilizing a five-point Likert scale that ranged from 1 (strongly disagree) to 5 (strongly agree). The accountability were measured by using 12 items that adapted from the study of Geer (2009) and Shaoul et al. (2012). Table 1 represents the measured items used in this study.

Table 1: Factors of measuring the accountability in the Malaysian public sector

\begin{tabular}{cl}
\hline Code & \multicolumn{1}{c}{ Description of Items } \\
\hline AC1 & $\begin{array}{l}\text { Ensures that there is a strategy for regular and effective communication with all stakeholders- } \\
\text { public, customers, funders, etc. }\end{array}$ \\
AC2 & $\begin{array}{l}\text { Supports the process of learning from mistakes and successes, ensuring that external views are } \\
\text { taken into account. }\end{array}$ \\
AC3 & $\begin{array}{l}\text { Upholds and applies the principles of equality and diversity and ensures that we are fair and } \\
\text { open to all sections of the community. }\end{array}$ \\
AC4 & $\begin{array}{l}\text { Recognizes the organization's responsibilities towards its wider communities, society, and the } \\
\text { environment. }\end{array}$ \\
AC5 & Sets clear operating goals to be achieved every year.
\end{tabular}


AC6 Maintains detailed and up-to-date records for supplies, office equipment, and other department.

AC7 Fosters collaboration with other related agencies as well as with other organizations.

AC8 Ensures that funds are used properly and appropriately in the manner approved by the authority.

AC9 Provides complaints and redress mechanism.

AC10 Produces several performance measures concerning the quality of services.

AC11 Places high responsibility on its employee to be highly efficient and effective.

AC12 Places high emphasis on giving prompt assistance to resolve enquiries or complaints from the customers.

\section{Analysis of Data}

The collected data was analysed using the descriptive statistics and factor analysis technique. Descriptive statistics is normally utilized to analyse the overall features of the data; on the other hand, factor analysis was utilized to calculate data consistency in the study. In addition, the data reliability was measured by utilizing the Cronbach's alpha test, and data normality was examined by Skewness and Kurtosis tests. Lastly, the data validity was tested by using Kaiser-Meyer Olkin test and Barlett's test.

\section{Findings and Discussion}

\section{Demographic Profiles}

The respondents were asked to provide some demographic information, including gender, ethnicity, age, academic qualification, type of qualification, job position, department, grade, and working experience. Table 2 provides the summary of the demographic information.

Table 2: Respondents' demographic information

\begin{tabular}{llcc}
\hline \multicolumn{1}{c}{ Demographic Profiles } & $\begin{array}{c}\text { Frequency } \\
(\mathbf{N = 1 9 4 )}\end{array}$ & $\begin{array}{c}\text { Percentage } \\
(\mathbf{\%})\end{array}$ \\
\hline Gender & Male & 79 & 40.7 \\
& Female & 115 & 59.3 \\
\hline Ethnicity & Malay & 176 & 90.7 \\
& India & 11 & 5.7 \\
& Chinese & 7 & 3.6 \\
\hline Age & $20-30$ years & 24 & 12.4 \\
& $31-40$ years & 64 & 33.0 \\
& $41-50$ years & 74 & 38.1 \\
& 51 years and above & 32 & 16.5 \\
\hline Academic Qualifications & Degree & 100 & 51.5 \\
& Master & 90 & 46.4 \\
& PhD & 4 & 2.1 \\
\hline Types of Qualifications & Accounting & 98 & 50.5 \\
& Non Accounting & 96 & 49.5 \\
\hline Job Position & Supporting Staff & 7 & 3.6 \\
& Management and & 176 & 90.7 \\
& Professional & & \\
& Top Management & 11 & 5.7 \\
\hline Department & Accounting & 45 & 23.2 \\
& Administrative & 78 & 40.2 \\
& Auditing & 10 & 5.2 \\
& Finance & 46 & 23.7 \\
& Others & 15 & 7.7 \\
\hline
\end{tabular}




\begin{tabular}{llcc}
\hline Grade & 41 & 101 & 52.1 \\
& 44 & 21 & 10.8 \\
& 48 & 70 & 36.1 \\
& 52 & 2 & 1.0 \\
\hline Working Experience in the & Less than 1 year & 11 & 5.7 \\
Current Organization (no. of & $1-3$ years & 10 & 5.2 \\
years) & $4-5$ years & 23 & 11.9 \\
& 5 years and above & 150 & 77.3 \\
\hline
\end{tabular}

The result of the demographic profile shows that $59.3 \%$ of the respondents were female. As much as 38\% of the respondents were in $41-50$ years old age group followed by $33 \%$ in 31-40 years old age group. Most of the respondents were Malays, comprising of $90.7 \%$. All the respondents had a minimum qualification of a bachelor degree.

The job position of $90.7 \%$ of the respondents shows that they were at management level and professionals. $40 \%$ of the respondents were in the administrative job scheme and $23.7 \%$ were in financial services, with only $5.2 \%$ in auditing job scheme. The remaining 7.7\% were from other different departments, such as officers in the tax, legal, health, education, information \& technology, and procurement departments. $52.1 \%$ of the respondents were from Grade 41, with $36.1 \%$ in Grade 48, and $10.8 \%$ in Grade 44. Those with more than 5 years working the present organization stood at $77 \%$ and $12 \%$ had 4 to 5 years working in the present organization.

\section{Factor Analysis}

Factor analysis was used to ensure the variable consistency and to determine the accountability. In this study, the factor loading of all the items were higher than 0.5 with exceptions on item AC10 as shown in Table 4. Thus, after removing this item, the factor loading values ranged from 0.5 (AC3) to 0.74 (AC4). It shows that 11 out 12 variables were usable in measuring accountability of the Malaysian public sector.

\section{Descriptive Analysis}

\section{Evaluation by Service Schemes}

Based on all the groups of service schemes, the average highest result for all the accountability factors were measured at 4.5 by the group on administrative scheme, and the mean lowest score was measured at 4.2 by the group on education scheme (Table 3 ). In addition, schemes on audit was less than the average overall score.

Table 3: Accountability factors based on the service schemes

\begin{tabular}{lcccccccccccccc}
\hline Service Schemes & AC1 & AC2 & AC3 & AC4 & AC5 & AC6 & AC7 & AC8 & AC9 & AC10 & AC11 & AC12 & $\begin{array}{c}\text { All } \\
\text { Average }\end{array}$ \\
& & 4.2 & 4.0 & 4.4 & 4.3 & 4.2 & 4.3 & 4.4 & 4.2 & 4.3 & 4.2 & 4.4 & 4.2 & 4.2 \\
Accounting & 4.4 & 4.0 & 4.6 & 4.7 & 4.4 & 4.6 & 4.6 & 4.4 & 4.6 & 4.3 & 4.7 & 4.3 & 4.5 \\
Administrative & 4.3 & 4.1 & 4.1 & 4.7 & 4.3 & 4.4 & 3.9 & 4.1 & 4.3 & 4.4 & 4.5 & 4.3 & 4.3 \\
Audit & 4.3 & 4.0 & 4.6 & 4.6 & 4.4 & 4.5 & 4.6 & 4.4 & 4.7 & 4.4 & 4.6 & 4.3 & 4.4 \\
Finance & 4.2 & 4.1 & 4.3 & 4.3 & 4.3 & 3.9 & 4.3 & 4.1 & 3.9 & 4.1 & 4.2 & 4.3 & 4.2 \\
Others & 4.3 & 4.0 & 4.5 & 4.5 & 4.3 & 4.5 & 4.5 & 4.3 & 4.5 & 4.3 & 4.5 & 4.3 & 4.4 \\
\hline Mean & 0.54 & 0.70 & 0.50 & 0.74 & 0.57 & 0.58 & 0.59 & 0.64 & 0.61 & $0.39 *$ & 0.73 & 0.54 & \\
Factor Loading & * & \multicolumn{10}{c}{ The factor loadings of the parameters less than 0.5 are considered as not suitable to measure accountability } \\
for Malaysian public sector
\end{tabular}


The group on accounting service scheme scored a total average of 4.2; on the other hand, its highest score was measured at 4.4 for AC3, AC7, and AC11. Moreover, the score for factors AC2 was lower compared to the average accountability scores of the group. The group on administrative scheme's average total score was measured at 4.5; on the contrary, the highest score was measured at 4.7 for the AC4 and AC11 factors. In addition, the lowest score was measured at 4.0 for AC2 factors. Moreover, the score for AC1, AC5, AC8, AC10, and $\mathrm{AC} 12$ were lower than the average accountability scores of the group. The group on audit scheme's average total score was measured at 4.3; on the other hand, the highest score was measured at 4.7 for the AC4 factor, and the lowest score measured at 3.9 for the AC7 factor. Moreover, scores for the factors of AC2, AC3, and AC8 were lower compared to the average accountability scores of the group. The group finance scheme's average total score was measured at 4.4; on the contrary, the highest score was measured at 4.7 for the AC9 factor, and the lowest score was measured at 4.0 for AC2 factors. Additionally, the accountability scores for $\mathrm{AC} 1$ and $\mathrm{AC} 12$ were lower compared to the overall average accountability scores of the group.

\section{Evaluation by Accountability Factors}

The study attempted to measure the accountability practice in the public sector, using 12 items. Based on the respondents, a total average of $94.9 \%$ agreed that they practiced the accountability factors as shown in Table 4. Based on all the factors of accountability, the highest mean score was at 4.5 level for factors AC3, AC4, AC6, AC7, AC9, and AC11. However, the lowest mean score was at 4.0 level for factor AC2 as shown in Table 3.

Table 4: Frequency scores of factors of accountability

\begin{tabular}{lrrrrrrrrrrrrr}
\hline \multicolumn{1}{c}{ Score } & AC1 & AC2 & AC3 & AC4 & AC5 & AC6 & AC7 & AC8 & AC9 & AC10 & AC11 & $\begin{array}{c}\text { AC12 } \\
\text { All } \\
\text { Average }\end{array}$ \\
\hline 1 & 0 & 0 & 0 & 0 & 0 & 0 & 0 & 0 & 0 & 0 & 0 & 0 & 0.0 \\
2 & 0 & 0 & 0 & 0 & 0 & 4 & 1 & 0 & 2 & 0 & 0 & 1 & 0.7 \\
3 & 6 & 6 & 10 & 12 & 6 & 10 & 12 & 9 & 13 & 10 & 9 & 7 & 9.2 \\
4 & 128 & 177 & 75 & 66 & 118 & 73 & 72 & 121 & 66 & 118 & 74 & 126 & 101.2 \\
\multicolumn{1}{c}{} & 60 & 11 & 109 & 116 & 70 & 107 & 109 & 64 & 113 & 66 & 111 & 60 & 83.0 \\
\hline Disagree (1-2) & 0 & 0 & 0 & 0 & 0 & 4 & 1 & 0 & 2 & 0 & 0 & 1 & 0.7 \\
Agree (4-5) & 188 & 188 & 184 & 182 & 188 & 180 & 181 & 185 & 179 & 184 & 185 & 186 & 184.2 \\
Disagree (1-2) $\%$ & 0.0 & 0.0 & 0.0 & 0.0 & 0.0 & 2.1 & 0.5 & 0.0 & 1.0 & 0.0 & 0.0 & 0.5 & 0.3 \\
Agree (4-5) $\%$ & 96.9 & 96.9 & 94.8 & 93.8 & 96.9 & 92.8 & 93.3 & 95.4 & 92.3 & 94.8 & 95.4 & 95.9 & 94.9 \\
Minimum & 3 & 3 & 3 & 3 & 3 & 2 & 2 & 3 & 2 & 3 & 3 & 2 & 3 \\
Maximum & 5 & 5 & 5 & 5 & 5 & 5 & 5 & 5 & 5 & 5 & 5 & 5 & 5 \\
Std. Dev. & 0.5 & 0.3 & 0.6 & 0.6 & 0.5 & 0.7 & 0.6 & 0.5 & 0.7 & 0.6 & 0.6 & 0.5 & 0.3 \\
\hline
\end{tabular}

In terms of the results of the study, based on the factors on practicing accountability in the public sector, $96.9 \%$ of the respondents claimed that they ensure there is a strategy for regular and effective communication with all stakeholders-public, customers, funders etc. (AC1) as shown in Table 4. The employees who used the scheme on administrative regarded it the most, and the employees who made use of the scheme on accounting perceived it to be the least as that can be observed in Table 3 .

However, $96.9 \%$ of the participants regarded the point of view, i.e. supports the process of learning from mistakes and successes, ensuring external views are taken into 
account (AC2) as that can be observed in Table 4; on the other hand, the employees who used the scheme on audit perceived it as the most in comparison with other schemes.

$94.8 \%$ of the participants agreed on the aspect, which is upholds and applies the principles of equality and diversity and ensures that we are fair and open to all sections of the community. (AC3) as that can seen in Table 4. The employees who used the scheme on administrative and finance were in the opinion that they possessed it the most; on the contrary, the employees who made use of the scheme on audit opined that they possessed it the least as shown in Table 3.

$93.8 \%$ of the participants agreed that they recognize the organization's responsibilities towards its wider communities, society and the environment (AC4) as shown in Table 4. The employees who made of use of the scheme on administrative and audit schemes remarked that they possessed it the most; on the other hand, the employees who used the scheme on accounting possessed it the least as shown in Table 3.

96.9\% of the participants agreed that they set clear operating goals to be achieved every year. (AC5) as shown in Table 4. The employees who used the scheme on administrative and finance considered that they possessed it the most; however, the employees who used the scheme on accounting scheme possessed it the least as it can be observed in Table 3.

$92.8 \%$ of the participants agreed that they maintain detailed and up-to-date records for supplies, office equipment and other department (AC6) as shown in Table 4. The employees who used the scheme on administrative reckoned that they possessed it the most; on the contrary, the employees who used the scheme on accounting opined that they possessed it the least as shown in Table 3. Based on the results of the other schemes on service, it is observed that employees in the audit scheme practiced it lesser compared to the average level.

93.3\% of the participants agreed that they foster collaboration with other related agencies as well as other types of organization (AC7) as shown in Table 4. The employees who used the scheme on administrative and finance has the feeling that they practiced it the most; on the contrary, the employees who used the scheme on audit reckoned that they practiced it the least as shown in Table 3. Based on the results of the other schemes on service, it can be mentioned that employees in the accounting scheme practiced it lesser compared to the average level.

Only $95.4 \%$ of the participants agreed that they ensure funds are used properly and in the manner authorized (AC8) as shown in Table 4. This suggests that the employees who used the scheme on administrative and finance possessed it the most; on the other hand, the employees who used the scheme on audit opined that they possessed it the least as shown in Table 3. Based on the results of the other schemes on service, it is observed that employees in the accounting scheme practiced it lesser compared to the average level.

Only $92.3 \%$ of the participants agreed that they provide complaints and redress mechanism (AC9) as shown Table 4. This signifies that the employees who used the scheme on finance practiced it the most; on the other hand, the employees who used the scheme on accounting and audit put forward the opinion that they practiced it the least as shown in Table 3. 
95.4\% of the participants agreed that they place high responsibility on its employee to be highly efficient and effective (AC11) as shown in Table 4. For AC11, it is observed that the participants in the administrative scheme practiced it the most; on the other hand, those in the accounting scheme practiced it the least as shown in Table 3.

95.9\% of the participants agreed that they place high emphasis on giving prompt assistance to resolve enquiries or complains from customer (AC12) as it is observed in Table 4. This suggests that the participants in the accounting scheme practiced it the less than other scheme as shown in Table 3.

\section{Diagnostic Tests}

Skewness and Kurtosis tests were used to carry out the normality testing. Skewness can be defined as something that out of the line, depends on the extension of the curve if it curves out to the right or left. When the curve extends more to the right, this is known as positively skewed, and when it extends more to the left, this is known as negatively skewed (Wuensch, 2014). On the other hand, Kurtosis measures how flat the symmetric distribution is at the top. The rule that is maintained for both the skewness and kurtosis to be considered normally distributed if the values range from -2 to +2 . When the skewness and kurtosis values are in this range, the data distribution is considered normal. Nevertheless, in this study, the skewness value was -2.21 ; on the other hand, the value of the kurtosis was 6.28 , and this indicates that the values are outside of the range of normality. This further signifies that the data was not normally distributed. However, Field (2013) suggests that the data can be considered normal if they exceed thirty, and the sample size of the study was 194.

Table 5: Reliability testing for factors of accountability

\begin{tabular}{lr}
\hline Cronbach's Alpha & 0.826 \\
Eigenvalue & 8.2 \\
Eigen \% variance & 82.61 \\
\hline \% of variance & 82.61 \\
Kaiser-Meyer-Olkin Measure of Sampling Adequacy & 0.6 \\
Bartlett's Test of Sphericity Approx. Chi-Square & 2616.499 \\
Bartlett's Test of Sphericity Sig. & 0.00000 \\
\hline
\end{tabular}

The Cronbach's alpha value on accountability as shown in Table 5 is 0.826 , which means that the reliability of the items in the questionnaire was excellent (George \& Mallery, 2016). The test's eigenvalues indicate that the factors utilized for accountability was able to explain $82.61 \%$ of the variance. The Kaiser-Meyer Olkin test shows the value of 0.6. The Barlett's Test Sphericity Approx. Chi-Square determines the value's significance (Chi-Square $=2616, \mathrm{p}<0.0000001)$. Thus, the sample was adequate for utilization in the factor analysis for measuring the accountability.

\section{Conclusions and Policy Recommendations}

Malaysia has a vision of reaching a developed nation status by the 2020; however, many steps must be undertaken to improve the accountability level of the public service sector. By evaluating the effects of 12 factors, this study attempted to measure the level of the present accountability practices in the Malaysian public sector. 
A total of $94.9 \%$ respondents claimed that in general, they practiced the mentioned factors of accountability; nevertheless, various service schemes prioritized the 12 factors differently. Overall, the practices of accountability in administration scheme group was the highest, and accounting scheme group was the lowest. On the other hand, the practices of accountability in the audit scheme group was lower in comparison with the general average score. The reasons might be for the presence of several areas of weaknesses, corruption, and weak controls of asset management that were reported in the recent official report by the Auditor General.

The government continuously initiates programmes that aim to promote and motivate the practices of accountability in all the departments in the public sector with a view to equip the personnel in the respective department to be more transparent in carrying out their duties. However, the initiation has not given the expected impact as reported in the 2014 Corruption Perception Index (CPI) by Transparency International, in which Malaysia only has improved by three ranks from 53 to 50 among 175 countries; this shows that the measures and efforts undertaken for fighting graft are still insufficient (Zainal, 2014). This demonstrates that although the government has taken the right steps to improve the public's perception, there are still many more steps that must be undertaken to increase the confidence of the public towards the good governance of the public sector.

It is not suffice just to simply change the structures of bureaucracy to improve this situation. The whole public sector must be transformed to create an efficient and reliable sector and to ensure adequate accountability and an effective evaluation system (Said et al. $2015,2016)$. Improvements in the accountability practices could assist the achievement of the intentions of the stakeholders and make sure there is accountability in the public sector. It is also recommended that each department and ministry produces or reports its activities of accountability and ethics and ensures that the respective ministry creates a culture of good governance in the various departments in the public sector. The report should be made available to the public to create awareness and to educate them on the important steps that have been undertaken to reduce employee misconduct in the government.

The findings of the study would be able to assist the various departments and agencies in the government to improve their level of accountability in accordance with the related service schemes. In addition, the factors of accountability measures and approaches utilized in this study could assist the government in creating techniques for the measurements of accountability in the public sector. Nevertheless, this study also faced several limitations that could be addressed in future researches. In this study, only 6 ministries were taken into consideration even though there are 24 ministries in Malaysia; on the other hand, the survey only included heads of departments. The levels of accountability practices could be different in the other ministries and among other government officers that could be addressed in future researches.

\section{References}

Almquist, R., Grossi, G., Helden, G. J. v. \& Reichard, C. (2013). Public sector governance and accountability. Critical Perspectives on Accounting, 24(7-8), 479-487.

Aziz, M. A. A., Rahman, H. A., Alam, M. M. \& Said, J. (2015). Enhancement of the accountability of public sectors through integrity system, internal control system and leadership practices: A review study. Procedia Economics and Finance, 28, 163-169. 
Bhuiyan, S. H. \& Amagoh, F. (2011). Public sector reform in Kazakhstan: Issues and perspectives. International Journal of Public Sector Management, 24(3), 227-249.

Christensen, M. \& Skærbæk, P. (2007). Framing and overflowing of public sector accountability innovations: A comparative study of reporting practices. Accounting, Auditing \& Accountability Journal, 20(1), 101-132.

Field, A. (2013). Discovering Statistics Using IBM SPSS Statistics. SAGE Publications, 4th Edition.

Gabriel, A. G. (2017). Transparency and accountability in local government: Levels of commitment of municipal councillors in Bongabon in the Philippines, Asia Pacific Journal of Public Administration, 39(3), 217 -223.

Geer, B. W. (2009). Nonprofit Accountability: An institutional and resource dependence lens on conformance and resistance. (Doctor of Philosophy), University of Pittsburgh.

George, D., \& Mallery, P. (2016). IBM SPSS Statistic 23 Step by Step: A simple guide and reference. $14^{\text {th }}$ Edition, New York: Routledge, Taylor \& Francis.

Gray, R., Bebbington, J. \& Collison, D. (2006). NGOs civil society and accountability: Making the people accountable to capital. Accounting, Auditing \& Accountability Journal, 19(3), 319-348.

Green, M., Vandekerckhove, W. \& Bessire, D. (2008). Accountability discourses in advanced capitalism: Who is now accountable to whom? Social Responsibility Journal, 4(1/2), 198-208.

https://trainingmag.com/age-accountability-workplace

Huse, M. (2005). Accountability and Creating Accountability: A Framework for Exploring Behavioural Perspectives of Corporate Governance. British Journal of Management, 16, S65-S79.

Isandla Institute (2017). Navigating Accountability and Collaboration in Local Governance, GGLN Reference Group Cape Town. June 2017. http://www.ggln.org.za/

Iyer, D. (2011). Tying performance management to service delivery: Public sector reform in Malaysia, 2009-2011. Innovations for Successful Societies, Princeton University.

Iyoha, F. O. \& Oyerinde, D. (2010). Accounting insfrastructure and accountability in the management of public expenditure in developing countries: A focus on Nigeria. Critical Perspectives on Accounting, 21, 361-373.

Jayasinghe, K. \& Soobaroyen, T. (2009). Religious spirit and people's perceptions of accountability in Hindu and Buddhist religious organizations. Accounting, Auditing \& Accountability Journal, 22(7), 997-1028.

Jorge de Jesus, M. A. \& Eirado, J. S. B. (2012). Relevance of accounting information to public sector accountability: A study of Brazilian federal public universities. Tékhne, 10(2), 87-98.

King, G. R. (1992). Back to accountability. Management Decision, 30(3), 9-11.

Lægreid, P., Verhoest, K. \& Jann, W. (2008). The governance, autonomy and coordination of public sector organizations. Public Organization Review, 8(2), 93-96.

Morrell, K. (2009). Governance and the public good. Public Administration, 87(3), 538-556.

Nyamori, R.O., Abdul-Rahaman, A.S. \& Samkin, G. (2017). Accounting, auditing and accountability research in Africa: Recent governance developments and future directions. Accounting, Auditing \& Accountability Journal, 30(6), 1206-1229.

Nyland, K. \& Pettersen, I. J. (2015). Hybrid controls and accountabilities in public sector management: Three case studies in a reforming hospital sector. International Journal of Public Sector Management, 28(2), 90-104.

Prosen, B. (2006). How leaders increase accountability and results. Accounting Today. 
Roberts, J. \& Scapens, R. (1985). Accounting systems and systems of accountability Understanding accounting practices in their organisational contexts. Accounting, Organizations and Society, 10(4), 443-456.

Said, J., Alam, M.M., \& Aziz, M.A. (2015). Public Accountability System: Empirical Assessment of Public Sector of Malaysia. Asian Journal of Scientific Research, 8(2), 225-236.

Said, J., Alam, M.M., \& Khalid, M. (2016). Relationship between Good Governance and Integrity System: Empirical Study on the Public Sector of Malaysia. Humanomics, 32(2), 151-171.

Shaoul, J., Stafford, A. \& Stapleton, P. (2012). Accountability and corporate governance of public private partnerships. Critical Perspectives on Accounting, 23(3), 213-229.

Subramaniam, N., McManus, L. \& Zhang, J. (2009). Corporate governance, firm characteristics and risk management committee formation in Australian companies. Managerial Auditing Journal, 24(4), 316-339.

Weinstein, M. (2017). The Age of Accountability in the Workplace, Training Magazine.

Wuensch, K. L. (2014). Skewness, Kurtosis and the Normal Curve. $\mathrm{http}: / /$ core.ecu.edu/psyc/wuenschk/StatsLessons.htm

Yaakob, A. F., Kadir, N. A. \& Jusoff, K. (2009). Accountability from the perspective of Malaysian Governance. Journal of Politics and Law, 2(3), 48-60.

Zainal, H. (2014). Malaysia climbs up three places in Corruption Index, The Star, 3 December. Retrieve from http://www.thestar.com.my/news/nation/2014/12/03/cpimalaysia-50-improves-two-places/ 